\title{
4. Die Nachbarvölker
}

Die Nachbarvölker der Isaurier, eine Reihe von kleineren, wohl ethnisch verwandten Stämmen, haben es nicht zu deren Berühmtheit gebracht und gehen in der Spätantike in den Isauriern auf. Dennoch verfügten sie noch über eigene Traditionen und Selbstbewußtsein bis in die Hohe Kaiserzeit. So prägten die Kennatai von Diocaesarea noch Münzen unter Domitian, als Nachfolger von Olba, ebenso die Lalasseis aus Claudiopolis. Analog dazu bezogen die im pamphylisch-pisidisch-isaurischen Dreiländereck gelegenen Poleis Etenna (Gölcük Ören) und Cotenna (Gödene) ihre Namen von den Stämmen der Etenneis und der Cotenneis. ${ }^{1}$

$\mathrm{Ob}$ die Kietai, welche die Küstenlinie und die Kalykadnosmündung bewohnten, ethnisch ein isaurischer Stamm waren oder ein ursprünglich eigenständiger, der sich dann im Verlauf der Kaiserzeit den Isauriern angliederte, ist nicht zu bestimmen. ${ }^{2}$ Ihre Erwähnung bei Tacitus läßt jedoch darauf schließen, daß sie sich erst später den Isauriern anschlossen. Die Isaurier selbst sind in den erhaltenen Tacitus-Büchern zwar nicht genannt, doch verwendet er den Namen Isauricus. ${ }^{3}$ Der Name ihres Siedlungsraums, die Ketis, hat sich lange erhalten: er erscheint noch an der Wende zum 5. Jahrhundert in der Vita der Heiligen Thekla. ${ }^{4}$ Coropissus stilisierte sich noch in der Kaiserzeit als Metropolis der Ketis. ${ }^{5}$ Auch Anemurium war in hellenistischer Zeit eine Stadt der Kieten; ihre Münzen unter dem Klientelkönig Antiochos IV. von Kommagene (38-72 n. Chr.) sind mit KIHT $\Omega$ N beschriftet. ${ }^{6}$

Die Lalasseis und Kennatai waren in der Gegend zwischen Claudiopolis und Diocaesarea angesiedelt und unterstanden der Herrschaft der olbischen Priesterkönige, was diese auf dem Revers ihrer Münzen von 10/11-14/15 n. Chr. bis in die Zeit Getas dokumentierten. ${ }^{7}$ Vielleicht waren die Kennatai identisch mit den Kieten. ${ }^{8}$ Eirenopolis lag auf dem Stammesgebiet der Lakanatai, die wohl ein Unterstamm der Lalasseis waren. ${ }^{9}$

1 Strab. XII 7, 1; Pol. V 72, 3: eine Stadt oberhalb Selges im Gebirge. Zu Stanamoas und seiner Familie BM II Nr. 12f., vgl. Hopwood (1984); SARTRE (1991) 294; SyME / BIRLEY (1995) 220 setzen diese Stämme gleich.

2 ROugÉ (1966) 283 bezeichnet die Kieten als Isaurier ,au sens large du mot"; Jones ( $\left.{ }^{2} 1971\right) 212$ spricht sich für die spätere Eingliederung des Stammes aus; TIB 5,1 18. 301 s.v. 'Kētis' nennen die Kietai einen ,isaurischen Stamm“.

3 Tac, ann. III 62.

4 DAGRON Mir. (1978) 276, 340.

$5 \quad I G \mathrm{II}^{2} 3307=$ OGIS 574 aus Athen, zu Ehren Hadrians; vgl. MAGIE (1950) II 1364f., Anm. 40; MitFord (1980) 1233 u. Anm. 12; ZIEGLER (1999) 141.

6 CGC XLI.

7 CGC 119-123.

8 Ptol. V 8, 6 (,Olbasa“ zur Ketis); Robert (1963) 108, 426.

9 Ptol, V 8, 6. Von B. V. HEAD, Historia numorum. Oxford ${ }^{2} 1911$, 722, wird Eirenopolis als 
Die Gegend um den Trogitis-See bewohnten die pisidischen Homonadeis, der größte Nachbarstamm der Isaurier. ${ }^{10}$ Sie verfügten offenbar über eine gut organisierte Staatsform, denn Plinius zufolge besaßen sie ein (nicht lokalisiertes) zentrales oppidum namens Omana und 44 weitere castella. Sie wurden erst unter Augustus im Jahre 6 v. Chr. von Sulpicius Quirinus unterworfen. ${ }^{11}$ Ihr Siedlungsraum war auf der Wasserscheide zwischen Pisidien und Isaurien gelegen, mit dem Zentrum am Trogitis-See und nach Südwesten hin durch den Melas bei der pisidischen Stadt Selge (heute Zerk, amtlich Altinyayla) begrenzt. ${ }^{12}$ Das Bistum Umanada deckte sich wohl, wie der Name vermuten läßt, mit dem alten Stammesgebiet der Homonadeis. Es hatte zunächst zur Isauria gehört. Wohl im Zuge der Verkleinerung Isauriens und die Neubesetzung der Bistümer unter Valens 370 wurde es zwischen Lykaonien und Pamphylien geteilt. ${ }^{13}$

Münzstätte der Lakanatis-Münzen in Erwägung gezogen; vgl. HILD (1993) 221, Anm. 5.

10 Strab. XII 6, 3-5. XIV 5, 1; Plin. n.h. V 94; RAMSAY (1890) 335. (1917) 229 ff; Broughton (1933) 134 ff.; LEVICK (1967) 38-41. 203-214; JONES $\left({ }^{2} 1971\right)$ 135. 146; TIB 4, 240f.; SYME / BIRLEY (1995) 219-224.

11 RAMSAY (1917); SYME (1986); vgl. Kap. II.1.6.

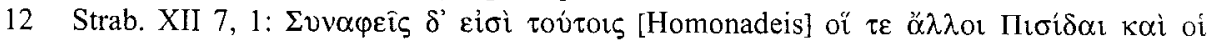

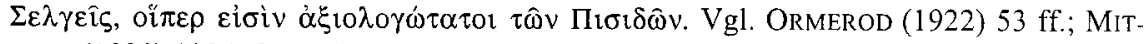
FORD (1980) 1234; SYME / BIRLEY (1995) 220.

13 TIB 4, 241 s.v. 'Umanada' gibt lediglich einen ,nicht genauer bestimmbaren Zeitpunkt vor $518^{\prime \prime}$ an. 